\title{
Fall-Associated Difficulty with Activities of Daily Living in Functionally Independent Individuals Aged 65 to 69 in the United States: A Cohort Study
}

\author{
Nishant K. Sekaran, MD, MSc, *广\$ Hwajung Choi, PhD, ${ }^{* \dagger}$ Rodney A. Hayward, MD, *广\& and \\ Kenneth M. Langa, MD, PhD*is
}

OBJECTIVES: To determine whether falling would be a marker for future difficulty with activities of daily (ADLs) that would vary according to fall frequency and associated injury.

DESIGN: Longitudinal analysis.

SETTING: Community.

PARTICIPANTS: Nationally representative cohort of 2,020 community-living, functionally independent older adults aged 65 to 69 at baseline followed from 1998 to 2008.

MEASUREMENTS: ADL difficulty.

RESULTS: Experiencing one fall with injury (odds ratio $(\mathrm{OR})=1.78,95 \%$ confidence interval $(\mathrm{CI})=1.29-2.48)$, at least two falls without injury $(\mathrm{OR}=2.36,95 \% \mathrm{CI}=1.80$ 3.09 ), or at least two falls with at least one injury $(\mathrm{OR}=3.75,95 \% \mathrm{CI}=2.55-5.53)$ in the prior 2 years was independently associated with higher rates of ADL difficulty after adjustment for sociodemographic, behavioral, and clinical covariates.

CONCLUSION: Falling is an important marker for future ADL difficulty in younger, functionally independent older adults. Individuals who fall frequently or report injury are at highest risk. J Am Geriatr Soc 61:96-100, 2013.

Key words: activities of daily living; falls; disability; older adults
D isability in older adults is an important public health concern. Recent studies document increasing disability in older Americans after 3 decades of decline. ${ }^{1,2}$ A recent analysis of the National Health and Nutrition Examination Surveys (NHANES) concluded that the rate of new disability increased in individuals aged 60 to 69 between 1998 and 2004. Minorities and overweight or obese individuals experienced higher rates of disability; the overall trend was independent of other measured sociodemographic factors, chronic conditions, and health behaviors. ${ }^{3}$ This finding suggests that younger groups of older adults may spend an increasing proportion of their lives with disability.

Falling is a common event in older adults and a known risk factor for future disability in individuals aged 75 and older. $^{4-6}$ Falls can result in injury, higher rates of skilled nursing home placement, high medical costs, and loss of patient confidence leading to voluntary restriction of activity. ${ }^{7-9}$ The relationship between falls and disability has not been systematically explored in younger groups of healthier older adults. Many of these individuals are newly retired and eligible for Medicare and may have the most to gain from earlier identification for future disability.

The relationship between falls and difficulty with activities of daily living (ADLs) was assessed in a nationally representative cohort of functionally independent, communityliving older adults aged 65 to 69 at baseline followed for 10 years. It was hypothesized that falling would be an important marker of future ADL difficulty that would vary according to fall frequency and associated injury.

\section{METHODS}

From the *Robert Wood Johnson Foundation Clinical Scholars Program; ${ }^{\dagger}$ Department of Internal Medicine, School of Medicine; ${ }^{\ddagger}$ Institute for Social Research, University of Michigan; and ${ }^{\S}$ Veterans Affairs Ann Arbor Healthcare System, Ann Arbor, Michigan.

Address correspondence to Nishant K. Sekaran, Department of Internal Medicine, University of Michigan Medical School and VA Ann Arbor Healthcare System, 3119 Taubman Center, 1500 East Medical Center Drive, SPC 5376, Ann Arbor, MI 48109. E-mail: nishants@umich.edu

DOI: $10.1111 /$ jgs. 12071

\section{Study Population}

Data from the Health and Retirement Study (HRS), a nationally representative, biennial longitudinal survey of adults aged 51 and older in the United States designed to evaluate the socioeconomic and health dynamics of older adults, were analyzed. The National Institute on Aging 
sponsors the HRS, and which the Institute for Social Research administers at the University of Michigan. The study uses a national probability sample of U.S. households, with systematic oversampling of black persons, Hispanic persons, and residents of Florida. Interviews are conducted in person and over the telephone and last for at least 1 hour, with approximately $40 \%$ of the interview devoted to health topics. Proxy respondents are permitted when the study participant is unable to participate because of physical or cognitive impairments. Records for survey respondents who die during the follow-up period are matched to the National Death Index. In accordance with the policy of the University of Michigan for this publicly available data source, this project was not submitted to the institutional review board.

For this longitudinal analysis, an initial sample of 2,120 community-living, functionally independent individuals (no difficulty with ADLs or instrumental ADLs (IADL), as defined below) without a proxy respondent, aged 65 to 69 at baseline, was selected from the 1998 HRS interview wave. Interview waves were defined as 2 -year periods (1998, 2000, 2002, 2004, 2006, and 2008). The subgroup represented $77 \%$ of all individuals aged 65 to 69 and approximately $10 \%$ of the entire 1998 HRS cohort. The analysis sample consisted of 1,998 individuals (8,486 measurement occasions) who completed at least two consecutive interview waves without missing data on ADL status in either interview and were not missing fall status data during the second interview. Within this analysis sample, $5.7 \%$ of the observations were missing covariate values, exclusive of falls or ADL difficulty status, yielding 8,001 observations for 1,985 individuals.

\section{Study Variables}

\section{Fall Status}

Interviewers asked respondents the following questions about falls during each interview wave: "Since the last interview period, did you fall?" "Since the last interview period, did you experience a fall that required medical attention (fall with injury)?" "Since the last interview period, how many falls did you experience?" The question pertaining to fall with injury is similar to questions used in other large national surveys. ${ }^{7}$ The severity of the fallrelated injury was not specified.

Categories of fall frequency and self-reported injury similar to those of Tinetti and Williams were created. ${ }^{6}$ The mutually exclusive fall status categories for each interview wave were, in the prior 2 years, no falls, one fall without injury, one fall with injury, at least two falls without injury, and at least two falls with at least one injury.

\section{Difficulty with ADLs}

Difficulty was defined as a limitation in performance of any one of six ADLs. The dichotomous outcome of no difficulty versus any difficulty during each survey wave was specified. The questions were framed as "Because of a health problem, do you have any difficulty with [activity]." The six ADLs were bathing, eating, dressing, walking across a room, getting into or out of bed, and toileting. A continuous composite measure of ADL difficulty (0-6) had been included in the previous interview to account for accrued or improved difficulty over the study follow-up period.

\section{Demographic and Health-Related Variables}

These covariates were selected based on their potential association with fall status or ADL difficulty and were classified according to a previously developed disability model $^{10}$ that includes sociodemographic factors, active pathology (chronic conditions), behavioral risk factors, impairment (dysfunction in one or more organ systems), and functional limitations. In addition to the previous ADL difficulty measure noted above, a continuous composite measure of IADL difficulty $(0-5)$ had also been included in the previous interview to account for accrued IADL difficulty over the study follow-up period. The five IADLs were using a telephone, taking medication, handling money, shopping, and preparing meals. The sociodemographic category included age, sex, race (white, black, Hispanic, other), education $(<12,12,>12$ years $)$, marital status, and household wealth quartiles $(<\$ 45,000, \$ 45,001-$ $134,000, \$ 134,001-319,000,>\$ 319,000)$. The health behavioral risk factors included body mass index (BMI), current alcohol use $(0,1-2,>2$ drinks per day), and smoking status at the 1998 cohort inception. The impairment domain included urinary incontinence, hearing, vision, self-reported memory impairment, self-reported health status, 8-item Center for Epidemiologic Studies Depression Scale depressive symptom score $(0,1-3$, $\geq 4$ symptoms), and chronic pain (mild, moderate, or severe on most days). The chronic condition categories were a self-reported physician-diagnosed history of cancer, hypertension, heart disease, stroke, diabetes mellitus, lung disease, and arthritis. Functional impairment included measures of mobility $(0$, $1-2, \geq 3$ limitations in walking several blocks, walking 1 block, walking across the room, climbing a flight of stairs, and climbing several flights of stairs) and strength $(0,1,2$, $\geq 3$ limitations in sitting for 2 hours, getting up from a chair, stooping, kneeling, crouching, and pushing or pulling a large object). For all covariate values with the exception of sex, race, and education, responses reported during the previous interview were used in the model.

\section{Statistical Analysis}

The relationship between fall status and ADL difficulty was evaluated over successive 2-year intervals during the 10 -year period. Multivariate logistic regression with clustering at the individual level was used to account for repeated measures. All statistical analyses were performed using Stata 12 (Stata Corp., College Station, TX). The model coefficients were used to estimate the average predicted adjusted risk of ADL difficulty for each of the five fall status groups (Stata 12 command predict).

The effect of missing data was tested by using multiple imputation with switching regression (Stata 12 command ice) for missing covariate values. The model remained robust to the imputation. The results are reported for the non-imputed model. The complex survey design was adjusted for using HRS probability weights (Stata 12 command svy). 


\section{RESULTS}

The 1998 baseline characteristics for the analysis sample are shown in Table 1 . The mean age \pm standard deviation of the respondents was $67.0 \pm 1.3,56 \%$ were female, and $79 \%$ were white. Seventy-five percent of the sample had one to three chronic conditions; $5 \%$ had four or more conditions. The most common conditions were arthritis $(52.8 \%)$, hypertension $(45.4 \%)$, and heart disease $(17.6 \%)$. Approximately $20 \%$ of individuals described themselves as having fair or poor health status at baseline. Mean body mass index was $27.0 \pm 4.6 \mathrm{~kg} / \mathrm{m}^{2}$.

Figure 1 shows the progression of the 1998 analysis cohort through the 10-year follow-up period. Over the 10-year period, $233(11 \%)$ individuals in the cohort died, and $1,819(85.6 \%)$ eligible individuals completed all follow-up interviews. The prevalence of ADL difficulty during each 2-year follow-up period ranged from a minimum of $10 \%$ to a maximum of $21 \%$, with a trend that increased over time. The prevalence of falling (data not shown) during each 2-year follow-up period ranged from a minimum of $19 \%$ to a maximum of $35 \%$, also with a trend that increased over time.

Logistic regression models were constructed according to the major domains described in a previously established disability model (Table 2). ${ }^{10} \mathrm{~A}$ measure of prior ADL and IADL difficulty reported during the previous interview was included in the base model to account for any change in fall status during the previous 2 years. After adjusting for a combination of sociodemographic, clinical, and functional covariates, one fall with injury $(\mathrm{OR}=1.78,95 \%$ $\mathrm{CI}=1.29-2.48)$, two or more falls without injury $(\mathrm{OR}=2.36,95 \% \mathrm{CI}=1.80-3.09)$, and two or more falls with at least one injury $(\mathrm{OR}=3.75,95 \% \mathrm{CI}=2.55-5.53)$ over the 2-year period were independently associated with ADL difficulty within 2 years. Experiencing one fall without injury in the prior 2 years was not.

The model coefficients were used to predict 2-year risk of ADL difficulty according to fall status (Table 2). The results suggest an adjusted risk of $7.3 \%$ in individuals who reported no falls during the observation period. This risk increased progressively with more-frequent and -severe falls, peaking to more than $39 \%$ for frequent falls with injury. Frequent falls with or without injury were strong predictors of ADL difficulty within 2 years for this functionally independent group of young older adults.

\section{DISCUSSION}

Fall status in the prior 2 years was an important independent predictor of subsequent ADL difficulty in a nationally representative, community-living, functionally independent cohort of individuals aged 65 to 69 at baseline followed for 10 years. An important finding of this study was that individuals who fell multiple times without receiving medical attention (the group with $\geq 2$ falls without injury) in the prior 2 years experienced a $17 \%$ greater risk of new ADL difficulty at 2 years than individuals with no falls.

Previous studies have shown the association between falls and ADL difficulty but did not include or were not sufficiently powered to test the association for individuals younger than $75 .{ }^{6}$ These younger individuals are newly
Table 1. Baseline Characteristics of the 1998 Health and Retirement Study Cohort Aged 65 to 69 without Difficulty in Activities of Daily Living or Instrumental Activities of Daily Living ( $N=2,120)$

\begin{tabular}{|c|c|}
\hline Demographic or Clinical Characteristic & Value \\
\hline Age, mean \pm standard deviation & $67 \pm 1.3$ \\
\hline \multicolumn{2}{|l|}{ Sex, $\%$} \\
\hline Male & 43.9 \\
\hline Female & 56.1 \\
\hline \multicolumn{2}{|l|}{ Race and ethnicity, \% } \\
\hline White & 79.4 \\
\hline Black & 12.3 \\
\hline Hispanic & 6.7 \\
\hline Other & 1.6 \\
\hline Married, $\%$ & 71 \\
\hline \multicolumn{2}{|l|}{ Household wealth, \$, \% } \\
\hline$<45,000$ & 19.2 \\
\hline $45,001-134,000$ & 23.9 \\
\hline $134,001-319,000$ & 24.7 \\
\hline$>319,000$ & 32.3 \\
\hline \multicolumn{2}{|l|}{ Education, years, \% } \\
\hline$<12$ & 24.1 \\
\hline 12 & 36.9 \\
\hline$>12$ & 39.0 \\
\hline \multicolumn{2}{|l|}{ Number of chronic conditions, $\%$} \\
\hline 0 & 19.4 \\
\hline $1-3$ & 75.3 \\
\hline$\geq 4$ & 5.1 \\
\hline \multicolumn{2}{|l|}{ Chronic condition, \% } \\
\hline Diabetes mellitus (no medications) & 3.1 \\
\hline Diabetes mellitus (medications) & 11.1 \\
\hline Arthritis & 52.8 \\
\hline Heart disease & 17.6 \\
\hline Prior stroke & 4.1 \\
\hline Lung disease & 8.1 \\
\hline Hypertension & 45.3 \\
\hline Cancer & 10.5 \\
\hline \multicolumn{2}{|l|}{ Self-reported health, \% } \\
\hline Excellent & 14.3 \\
\hline Very good & 31 \\
\hline Good & 34.5 \\
\hline Fair & 16.3 \\
\hline Poor & 3.9 \\
\hline \multicolumn{2}{|l|}{ Body mass index, $\mathrm{kg} / \mathrm{m}^{2}, \%$} \\
\hline$<18.5$ (underweight) & 0.75 \\
\hline $18.5-24.5$ (normal) & 29.9 \\
\hline 24.6-30.0 (overweight) & 46.8 \\
\hline$>30.0$ (obese) & 21.6 \\
\hline \multicolumn{2}{|c|}{ Centers for Epidemiologic Studies Depression Scale score, $\%^{\mathrm{a}}$} \\
\hline 0 & 46.9 \\
\hline $1-3$ & 43.1 \\
\hline$\geq 4$ & 10 \\
\hline Self-reported memory loss, $\%$ & 0.3 \\
\hline \multicolumn{2}{|l|}{ Chronic pain, \% } \\
\hline None & 81.6 \\
\hline Mild & 5.8 \\
\hline Moderate & 10.6 \\
\hline Severe & 2.1 \\
\hline Current smoker in 1998, \% & 14.3 \\
\hline \multicolumn{2}{|l|}{ Current alcohol use, drinks/d, \% } \\
\hline 0 & 68.4 \\
\hline $1-2$ & 24.7 \\
\hline$>2$ & 6.8 \\
\hline Urinary incontinence, \% & 12.4 \\
\hline
\end{tabular}

(Continued) 
Table 1. (Contd.)

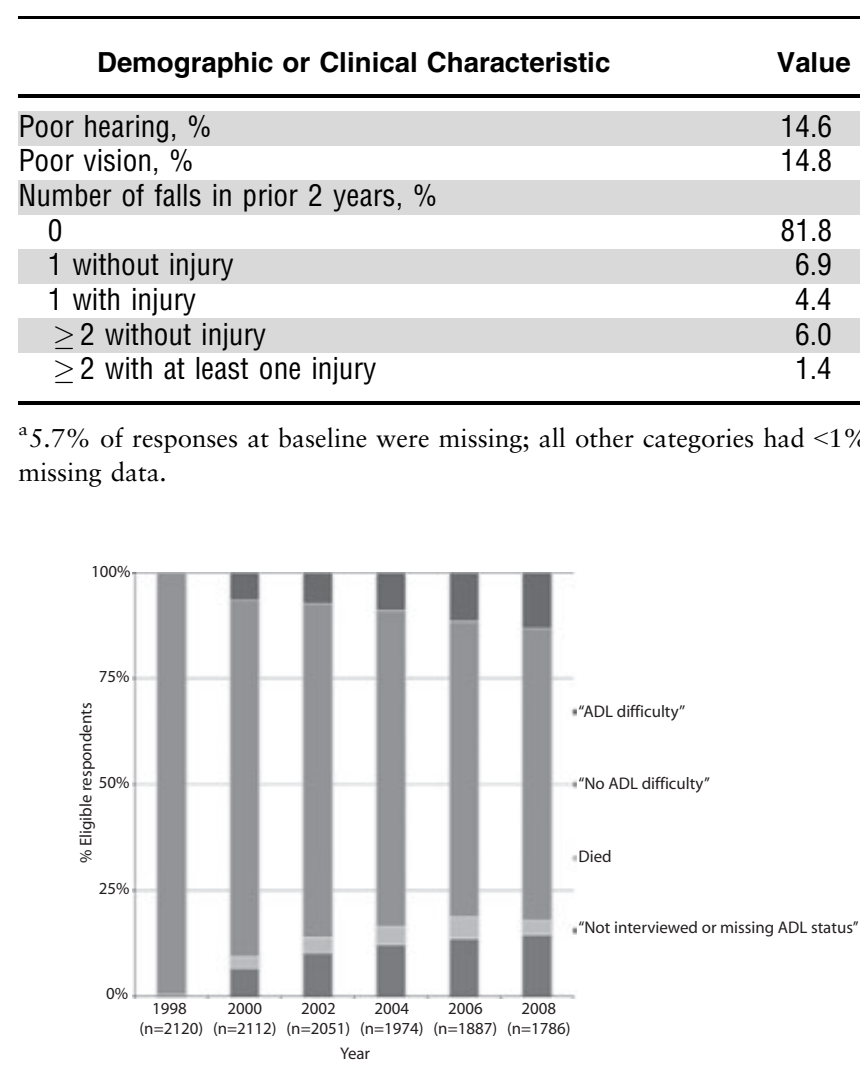

Figure 1. Longitudinal progression of the 1998 Health and Retirement Study cohort (no difficulty with activities of daily living or instrumental activities of daily living and aged 65-69 at baseline; $\mathrm{N}=2,120$ respondents).

eligible for Medicare services, are generally healthier, and may benefit from earlier targeted efforts to reduce future ADL difficulty. These efforts are important because ADL difficulty, even if transient, represents an important social cost for older adults, their families, and society.
There are several strengths to this observational analysis. First, the cohort was a nationally representative group of older adults who were close in age and functionally independent at baseline. Second, a comprehensive set of measures, including change in ADL or IADL difficulty over time and a detailed set of demographic and clinical characteristics (chronic disease status, body mass index, other geriatric conditions, and functional status) was assessed over time to improve measurement reliability. The fall status categories were similar to those of Tinetti and Williams, ${ }^{6}$ allowing levels of fall risk to be categorized based on frequency and severity. Third, the HRS data capture individuals who may never receive medical attention for fall-related problems and still be at high risk of subsequent ADL difficulty. This complements information from national surveillance databases (National Electronic Injury Surveillance System-All Injury Program and Healthcare Cost and Utilization Project) identifying nonfatal falls receiving medical attention.

There are several limitations of this study. First, the observational data obtained from the HRS are selfreported, and recall bias of falls is possible. A systematic review suggests more accurate recall in nonfallers and those falling with injury compared to individuals falling without injury. ${ }^{11}$ Recall bias would be more likely to lead to underestimation of ADL difficulty risk for less-severe falls. Second, although it was possible to capture ADL responses at the end of each wave, the data were not granular enough to establish temporal precedence between falls and ADL difficulty. Third, limited medication data were included in the model. Diabetes mellitus medication use was included as a proxy for diabetes mellitus severity, but psychoactive medication use (an established risk factor) was not included given uncertainty about data consistency. Fourth, although a comprehensive set of observed covariates was included, individuals who fall more frequently or severely are likely to have a distinct physiological phenotype that predisposes them to an accelerated path of functional decline. Causality cannot be inferred between falls

\begin{tabular}{|c|c|c|c|c|}
\hline \multirow[b]{2}{*}{$\begin{array}{l}\text { Fall Category (\% of } \\
\text { Observations) }\end{array}$} & \multicolumn{2}{|c|}{ Unadjusted Fall Risk $(n=8,486)^{a}$} & \multicolumn{2}{|c|}{ Adjusted Fall Risk $(\mathrm{n}=\mathbf{8 , 0 0 1})^{\mathrm{b}}$} \\
\hline & $\begin{array}{l}\text { Predicted Risk of ADL } \\
\text { Difficulty, } \%^{\circ}\end{array}$ & OR (95\% Cl) & $\begin{array}{l}\text { Predicted Risk of ADL } \\
\text { Difficulty, \% }\end{array}$ & OR (95\% Cl) \\
\hline 0 falls (74) & 7.5 & Reference & 7.3 & Reference \\
\hline 1 fall without injury (9.1) & 10.6 & $1.42(1.07-1.86)^{d}$ & 10.8 & $1.31(0.97-1.77)$ \\
\hline 1 fall with injury (4.5) & 15.3 & $2.16(1.59-2.94)$ & 14.3 & $1.78(1.29-2.48)^{\mathrm{e}}$ \\
\hline$\geq 2$ falls without injury (9.4) & 24.5 & $3.16(2.50-4.00)^{\dagger}$ & 24.5 & $2.36(1.80-3.09)^{\dagger}$ \\
\hline$\geq 2$ falls with injury (2.9) & 39.6 & $5.99(4.25-8.44)^{\dagger}$ & 39.9 & $3.75(2.55-5.53)^{\dagger}$ \\
\hline
\end{tabular}

${ }^{a}$ The unadjusted model includes a continuous measure (0-6) of lagged ADL and instrumental ADL (IADL) difficulty status reported in the previous interview.

${ }^{\text {b}}$ The fully adjusted model included ADL and IADL difficulty in the previous 2-year period and sociodemographic, health behavior, and clinical characteristics. The value during the previous 2-year interview period was used for all characteristics that can change over time.

${ }^{c}$ Predicted risk for ADL difficulty was calculated by inputting the observed values for each characteristic into the regression model and calculating the average risk for each fall category using the model coefficients.

${ }^{\mathrm{d}} P<.05$.

${ }^{\mathrm{e}} P<.01$.

${ }^{\mathrm{f}} P<.001$.

$\mathrm{n}=$ number of 2 -year observation periods across 1,985 subjects in the analysis sample; $\mathrm{OR}=$ odds ratio; $\mathrm{CI}=$ confidence interval. 
and subsequent ADL difficulty with this observational data. In addition, access was not available to physical performance data or clinical diagnostic information to include in the model.

Interviewees reported falling frequently and not seeking specific medical attention ( $\geq 2$ falls without injury) in nearly one in 10 cases. These individuals are at high risk of subsequent ADL difficulty. Several studies have found that medical providers do not perform comprehensive postfall assessments or teach individuals how to prevent future falls. ${ }^{12,13}$ An initial falls screen is easily obtained and can be as simple as inquiring whether an individual has fallen before. ${ }^{14}$ For individuals who report falling, assessment of hemodynamics, balance, visuospatial ability, medications, cognition, home environment, and ADL and IADL performance are important next steps. ${ }^{15}$ Motivating insurers, such as Medicare, to support comprehensive fall prevention and treatment programs may be an important policy intervention because these programs are also likely to address multiple predisposing risk factors for $\mathrm{ADL}$ difficulty. ${ }^{16}$

Future studies can evaluate functional ADL trajectories in younger groups of older adult fallers over time to obtain a better sense of how transient or persistent the associated difficulties may be.

\section{ACKNOWLEDGMENTS}

An abstract of the manuscript was presented at the Robert Wood Johnson Foundation Clinical Scholars National Meeting, November 2011. We would like to thank Anna $\mathrm{Xu}$, University of Michigan, for assistance with data management and Nick Moloci, BS, University of Michigan, for editing assistance.

Conflict of Interest: Dr. Hayward writes three chapters on cardiovascular prevention for UpToDate. Dr. Langa was supported by a grant from the National Institute on Aging (R01 AG030155). The National Institute on Aging sponsors the HRS (U01 AG009740), which the Institute for Social Research, University of Michigan administers. Dr. Sekaran is supported by a grant from the Robert Wood Johnson Foundation Clinical Scholars Program.

Author Contributions: Study concept and design: Sekaran, Choi, Hayward, Langa. Acquisition of subjects and data: Sekaran, Choi, Langa. Analysis and interpretation of data: Sekaran, Choi, Hayward, Langa. Preparation of manuscript: Sekaran, Choi, Hayward, Langa.

Sponsor's Role: The funding sources were not involved in the design, conduct, or reporting of this study.

\section{REFERENCES}

1. Martin LG, Freedman VA, Schoeni RF et al. Trends in disability and related chronic conditions among people ages fifty to sixty-four. Health Aff (Millwood) 2010;29:725-731.

2. Fuller-Thomson E, Yu B, Nuru-Jeter A et al. Basic ADL disability and functional limitation rates among older Americans from 2000-2005: The end of the decline? J Gerontol A Biol Sci Med Sci 2009;64A:1333-1336.

3. Seeman TE, Merkin SS, Crimmins EM et al. Disability trends among older Americans: National Health and Nutrition Examination Surveys, 1988-1994 and 1999-2004. Am J Public Health 2010;100:100-107.

4. Kiel DP, O'Sullivan P, Teno JM et al. Health care utilization and functional status in the aged following a fall. Med Care 1991;29:221-228.

5. Lips P, Stel VS, Smit JH et al. Consequences of falling in older men and women and risk factors for health service use and functional decline. Age Ageing 2004;33:58-65.

6. Tinetti ME, Williams CS. The effect of falls and fall injuries on functioning in community-dwelling older persons. J Gerontol A Biol Sci Med Sci 1998;53A:M112.

7. Stevens JA, Mack KA, Paulozzi LJ et al. Self-reported falls and fall-related injuries among persons aged $>$ or $=65$ years-United States, 2006. J Safety Res 2008;39:345-349.

8. Tinetti ME, Kumar C. The patient who falls: "It's always a trade-off." JAMA 2010;303:258-266.

9. Rubenstein LZ, Josephson KR. The epidemiology of falls and syncope. Clin Geriatr Med 2002;18:141-158.

10. Verbrugge LM, Jette AM. The disablement process. Soc Sci Med 1994;38: $1-14$.

11. Ganz DA, Higashi T, Rubenstein LZ. Monitoring falls in cohort studies of community dwelling older people: Effect of the recall interval. J Am Geriatr Soc 2005;53:2190-2194.

12. Rubenstein LZ, Solomon DH, Roth CP et al. Detection and management of falls and instability in vulnerable elders by community physicians. J Am Geriatr Soc 2004;52:1527-1531.

13. Shumway-Cook A, Ciol MA, Hoffman J et al. Fall in the Medicare population: Incidence, associated factors, and impact on health care. Phys Ther 2009;89:324-332.

14. Michael YL, Whitlock EP, Lin JS et al. Primary care relevant interventions to prevent falling in older adults: A systematic evidence review for the US Preventive Services Task Force. Ann Intern Med 2010;153:815-825.

15. Ganz DA, Bao Y, Shekelle PG et al. Will my patient fall? N Eng J Med 2007;297:77-86

16. Wu S, Keeler EB, Rubenstein LZ et al. A cost-effectiveness analysis of a proposed national falls prevention program. Clin Geriatr Med 2010;26:751-766. 